\title{
Screening for mutations of the cationic trypsinogen gene: are they of relevance in chronic alcoholic pancreatitis?
}

\author{
N Teich, J Mössner, V Keim
}

\begin{abstract}
Background-In hereditary pancreatitis mutations of exons 2 (N21I) and $3(\mathrm{R} 117 \mathrm{H})$ of the cationic trypsinogen gene have been described.

Aims-To investigate whether the same mutations can also be found in patients with chronic alcoholic pancreatitis.

Methods-Leucocyte DNA was prepared from 23 patients with chronic alcoholic pancreatitis, 21 with alcoholic liver cirrhosis, 34 individuals from seven independent families with hereditary pancreatitis, and 15 healthy controls. DNA was also obtained from pancreatic tissue $(n=7)$ and from pancreatic juice $(n=5)$ of patients suffering from chronic alcoholic pancreatitis. $\mathrm{R} 117 \mathrm{H}$ was detected by restriction digestion with Afl III. N21I was identified by an allele specific polymerase chain reaction (PCR).

Results-R117H was detected in four families with hereditary pancreatitis. The N21I mutation was identified in three families. All mutations were confirmed by sequencing of the corresponding DNAs. In patients with chronic alcoholic pancreatitis neither the exon 2 nor exon 3 mutations were present in blood leucocytes, pancreatic juice, or pancreatic tissue. DNA of the patients with alcoholic liver cirrhosis as well as all controls was of wild type.
\end{abstract}

Conclusions-The allele specific PCR may be used to screen for the N21I mutation of cationic trypsinogen. Both trypsinogen mutations were found in hereditary pancreatitis but do not seem to be major pathogenic factors in chronic alcoholic pancreatitis.

(Gut 1999;44:413-416)

Keywords: hereditary pancreatitis; polymerase chain reaction; trypsinogen mutation; cationic trypsinogen

Medizinische Klinik und Poliklinik II, Universität Leipzig, Leipzig, Philipp

Rosenthal Strasse 27, D-04103 Leipzig, Germany

$\mathrm{N}$ Teich

J Mössner

V Keim

Correspondence to: Dr Keim.

Accepted for publication 2 September 1998

The main cause of chronic pancreatitis in Western countries is excessive alcohol consumption. ${ }^{1}{ }^{2}$ There is, however, only limited information concerning the pathogenic mechanism by which alcohol leads to the disease. Several mechanisms such as duct obstruction by protein plugs, direct toxicity of ethanol, or oxidative stress have been proposed. ${ }^{12}$ Very recently, fatty acid ethyl esters, which are produced as metabolites of ethanol in the pancreas, were hypothesised to be of pathogenic relevance. ${ }^{3}$ However, none of these concepts has yet found enough experimental support to gain general acceptance.

Hereditary pancreatitis, on the other hand, is a rare autosomal dominant disease with $80 \%$ penetrance. $^{45}$ It is characterised by acute episodes of pancreatitis in early childhood followed by progressive exocrine and endocrine insufficiency. Recently, Whitcomb and coworkers identified mutations of the cationic trypsinogen gene $(\mathrm{R} 117 \mathrm{H}, \mathrm{N} 21 \mathrm{I})$ as high risk factors for this disease. ${ }^{6}{ }^{7}$ It was suggested that the altered trypsins were more stable against degradation by proteases. This, in turn, could lead to autodigestion of the gland as a result of the presence of increased amounts of active trypsin within the cell and to a chronic inflammatory pancreatic disease. ${ }^{6}$ Experiments with the mutated recombinant human trypsins have not yet been reported. However, the rat anionic trypsin mutation R $117 \mathrm{~N}$, which is different to its human counterpart, showed reduced autolysis, supporting this theoretical concept. ${ }^{8}$

The histological picture is similar in hereditary and chronic alcoholic pancreatitis ${ }^{9}$; indepth studies, however, have not been performed due to the limited availability of material. Chronic inflammation, pain, destruction of the exocrine and endocrine parts of the gland, as well as calculi may be found both in alcoholic and hereditary pancreatitis. Due to these clinical similarities there may be a common pathogenic pathway for the two diseases and it could be hypothesised that trypsinogen mutations may be of importance in both types of chronic pancreatitis. We therefore investigated whether the trypsinogen mutations $\mathrm{R} 117 \mathrm{H}$ and N21I were present in patients with chronic alcoholic pancreatitis.

\section{Methods}

All patients gave informed consent for use of their samples for the investigation. All materials were taken during routine diagnostic or therapeutic procedures.

In patients classified as suffering from chronic alcoholic pancreatitis average alcohol consumption was higher than $100 \mathrm{~g}$ per day for more than five years. Diagnosis was based on findings at endoscopic retrograde pancreatography (ERP) in all cases. The changes in duct morphology were graded according to the Cambridge classification. ${ }^{10}$ Activity of chymotrypsin (Boehringer Mannheim, Germany) and elastase (ScheboTech, Germany) in stool

Abbreviations used in this paper: ERP, endoscopic retrograde pancreatography; PCR, polymerase chain reaction. 
Table 1 Sequences and homologies of primers used for allele specific PCR

\begin{tabular}{|c|c|c|c|c|c|c|}
\hline & \multirow[b]{2}{*}{ Primer sequence $\left(5^{\prime}-3^{\prime}\right)$} & \multicolumn{5}{|c|}{ Per cent homology to trypsinogens $A-E$} \\
\hline & & $A$ (cationic) & $B$ & $C$ & $D$ & $E$ (anionic) \\
\hline Control (forward) & TGGTCATGGCCAGGTCTATGC & 100 & 95 & $<60$ & 76 & 90 \\
\hline Control (reverse) & ACAGTTAGCAGAGGTAGAGTG & 100 & $<60$ & $<60$ & 95 & 95 \\
\hline Mutation specific (reverse) & GGACAGAATTCTCCTCACAGA & Wild type 95 , mutation 100 & 95 & 95 & 95 & 100 \\
\hline
\end{tabular}

was determined. Values below $13 \mathrm{U} / \mathrm{g}$ (chymotrypsin) or $200 \mu \mathrm{g} / \mathrm{g}$ (elastase) were regarded as pathological. Patients with alcoholic liver cirrhosis had a mean alcohol consumption of above $80 \mathrm{~g}$ /day for more than four years. The diagnosis was confirmed by liver biopsy. Normal controls were recruited from the medical staff of the clinic and had no evidence of liver or pancreatic diseases (normal values for aminotransferases, chymotrypsin, or elastase in stool; no episodes of diarrhoea or steatorrhoea). Hereditary pancreatitis was suspected when a family history was present and/or when symptomatic children were involved. The disease was confirmed by detection of the cationic trypsinogen gene mutations (see below).

DNA was extracted from anticoagulated blood samples and pancreatic juice using the Micromix Ultra Fast Genomic DNA extraction kit (Talent, Italy). DNA from pancreatic resections was prepared as described previously. ${ }^{11}$ Exon 3 of cationic trypsinogen was amplified and the polymerase chain reaction (PCR) fragment digested with Afl III as described recently. ${ }^{6}$ For detection of the N21I mutation an allele specific PCR was used. The $40 \mu \mathrm{l}$ reaction solution contained 2.5 ng genomic DNA, $37.5 \mathrm{nmol} \mathrm{MgCl}_{2}, 200 \mathrm{fmol}$ control forward primer, $200 \mathrm{fmol}$ mutation specific reverse primer, 400 fmol control reverse primer, $7.5 \mathrm{nmol}$ of each deoxynucleotide triphosphate, and 1.5 U AmpliTaq DNA polymerase (Perkin Elmer). Table 1 shows the sequence of the respective primers as well as their homologies to the various trypsinogens. ${ }^{13}$ Cycling conditions consisted of an initial two

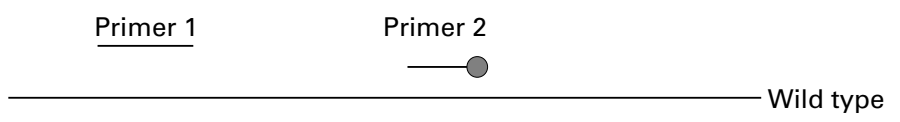

Amplification

Primer 3

$1018 \mathrm{bp}$

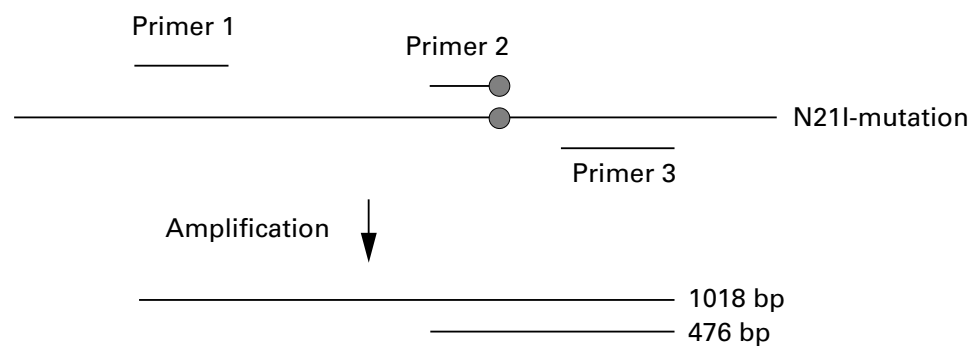

Figure 1 Schematic diagram of allele specific PCR. minute denaturation step at $94^{\circ} \mathrm{C}$, followed by 35 cycles at $94^{\circ} \mathrm{C}$ for 20 seconds, $65^{\circ} \mathrm{C}$ for 30 seconds, $72^{\circ} \mathrm{C}$ for 45 seconds, and a final seven minute elongation step at $72^{\circ} \mathrm{C}$. The annealing temperature was increased stepwise starting at $53^{\circ} \mathrm{C}$. At $59^{\circ} \mathrm{C}$ the primer annealing was specific while at temperatures of $67^{\circ} \mathrm{C}$ or higher no PCR product was detectable. The PCR products were separated by agarose gel electrophoresis and the bands were detected by ethidium bromide staining. Figure 1 shows the principle of the analytical procedure. In the presence of the N21I mutation, two bands of 1018 and $476 \mathrm{bp}$ are seen, whereas with wild type DNA only one band of $1018 \mathrm{bp}$ is seen on the gel.

In order to estimate the frequency of the mutant allele serial dilutions of mixtures of DNA with either the exon 2 mutation (N211) or exon 3 mutation $(\mathrm{R} 117 \mathrm{H})$ with wild type DNA were used. The percentage of mutated DNA varied from $0.005 \%$ to $50 \%$. A restriction digestion with Afl III as well as an allele specific PCR was performed with these samples.

\section{Results}

In 25 patients (all men, aged 34-62 years, median 45 years) with chronic pancreatitis the diagnosis had been made $0-5$ years (median 3.4) previously; abdominal symptoms had been present for $0-8$ years (median 4.2). The diagnosis of chronic pancreatitis was based on ERP. According to the Cambridge classification the grading in four patients was mild, in nine patients moderate, and in 12 patients severe. Chymotrypsin and elastase measurements in stool were pathological in all patients. In none was evidence for liver cirrhosis found, but five had increased aminotransferases, most likely due to ongoing alcohol consumption. There was no evidence of a family history of pancreatitis and in none was symptoms present before the onset of alcohol abuse. In patients in whom pancreatic tissue or juice was investigated the diagnosis was proved histologically or by ERP.

The DNA samples from patients with chronic alcoholic pancreatitis, alcoholic liver cirrhosis, and healthy controls were analysed for the exon 3 mutation $(\mathrm{R} 117 \mathrm{H})$ of the cationic trypsinogen gene. No evidence of an Afl III restriction site was found (data not shown). In four of the seven non-related families with hereditary pancreatitis restriction digestion with Afl III revealed evidence of the $\mathrm{R} 117 \mathrm{H}$ mutation, which was subsequently confirmed by sequencing of the corresponding DNA (data not shown).

In the three residual families with hereditary pancreatitis the exon 2 mutation was detected 
A I II

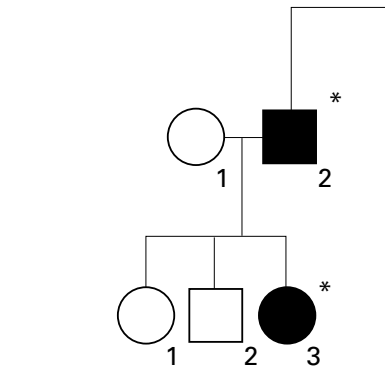

IV

B

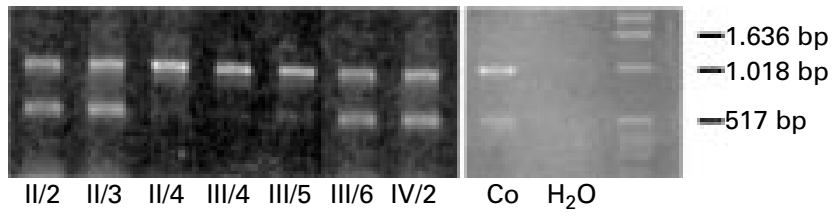

Figure 2 (A) Pedigree of a family with hereditary pancreatitis caused by N21I trypsin. The individuals with the disease are shown as closed symbols. An asterisk indicates the presence of a trypsinogen mutation. (B) Detection of exon 2 mutation (N21I) by allele specific PCR.

by the allele specific PCR. Figure 2A shows the pedigree of one of these families and fig $2 \mathrm{~B}$ the results of the analytical procedure. There was a close association between symptoms of pancreatitis (closed symbols) and the N21I mutation: only patients with this mutation suffered from the disease; the individuals with wild type
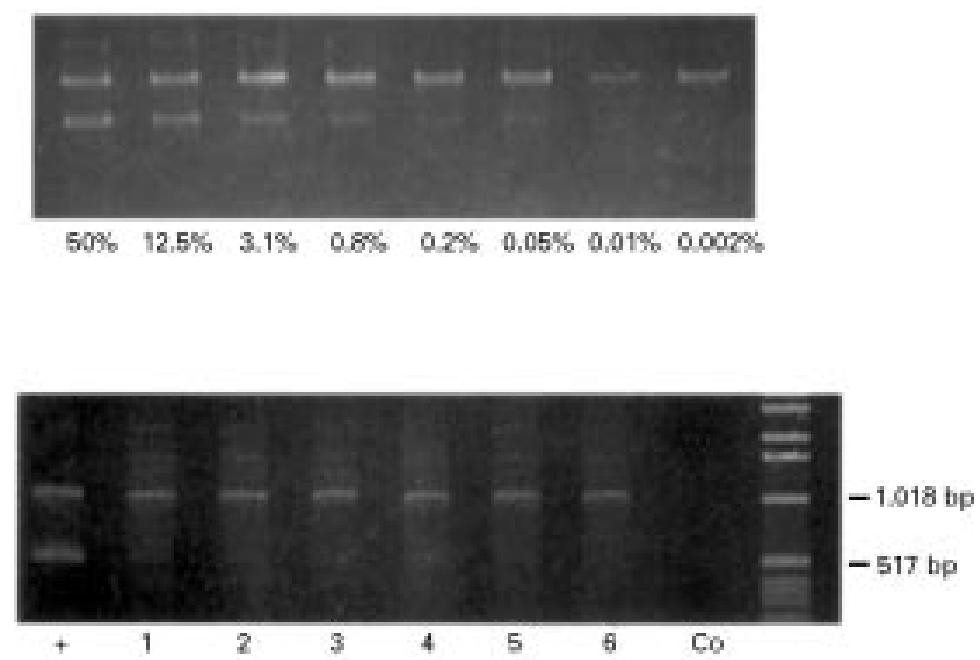

Figure 3 Allele specific PCR from serial dilution of N21I DNA with wild type DNA. The percentage of mutated DNA is indicated (top panel). Analysis of pancreatic juice (lanes 1-3) and pancreatic tissue (lanes 4-6) DNA from patients with chronic pancreatitis by allele specific PCR (bottom panel). trypsinogen did not. In this family we could identify one asymptomatic adult (individual II/3).

DNA mutated at N21I was diluted with wild type DNA and the mixture was analysed by allele specific PCR. As shown in fig 3, N21I DNA was detected at a 500-fold surplus of wild type DNA. DNA prepared from leucocytes, pancreatic tissue, and pancreatic juice of patients with alcoholic pancreatitis was also analysed by this technique; as with normal controls, no evidence of the N21I mutation was found (fig 3). DNA samples from normal controls and from patients with alcoholic liver cirrhosis were also of wild type (not shown).

Mixtures of wild type DNA with $\mathrm{R} 117 \mathrm{H}$ DNA were also used to detect this mutation at surplus of wild type DNA. With this technique the mutated DNA had to be present at concentrations of $10 \%$ or more to be detected with Afl III restriction digestion (not shown). When analysed with this technique the DNAs from pancreatic tissue or pancreatic juice obtained from individuals with chronic pancreatitis revealed no evidence of the $\mathrm{R} 117 \mathrm{H}$ mutation (data not shown).

\section{Discussion}

The pathogenesis of chronic pancreatitis is still an unresolved problem. As already mentioned, several different theories have been proposed, but none has been generally accepted. From the clinical standpoint similarities of symptoms of chronic alcoholic and hereditary pancreatitis are striking. ${ }^{12}$ When the onset of symptoms in patients with the inherited disease is late and when a familial relationship is not evident, it may be difficult to differentiate the two forms unless DNA analysis is available. Therefore, it is conceivable that hereditary and alcoholic pancreatitis arise via the same pathogenic mechanism and trypsinogen mutations or mosaics may well be of pathogenic relevance in chronic alcoholic pancreatitis.

However, the detection of these mutations is not trivial as eight trypsinogen genes were found on chromosome $7 \mathrm{q} 35 .{ }^{13}$ There were few differences between them: cationic and anionic trypsinogen, for example, share more than $90 \%$ of their coding sequences. ${ }^{13}$ In addition, the N21I mutation of cationic trypsinogen, the second highest risk factor for hereditary pancreatitis identified by Gorry and colleagues ${ }^{7}$ and confirmed by us, ${ }^{14}$ is present as wild type sequence in the anionic trypsinogen. ${ }^{13}$ With the technique described by Whitcomb et $a l,{ }^{6}$ the $\mathrm{R} 117 \mathrm{H}$ mutation may easily be screened for by restriction digestion of a PCR fragment, as the mutation creates a novel restriction site. This mutation has been detected in four of our seven families with hereditary pancreatitis and was confirmed by sequencing.

N21I situated in exon 2 of the cationic trypsinogen gene, however, may not be easily assayed. Therefore, an allele specific PCR was developed to identify this second highest risk factor for hereditary pancreatitis. The analytical principle is based on the fact that the activity of the polymerase is highly controlled by the $3^{\prime}$ end of the primer. ${ }^{15-17}$ At a mismatch the 
polymerase activity is largely inhibited so that specific amplification can be achieved by selection of adequate amplification conditions and primers. A similar technique has already been used for the detection of a variety of mutations, for example, in the Helicobacter pylori genome, ${ }^{15}$ Leber's hereditary optic neuropathy, a rare disease associated with mutations in mitochondrial DNA, ${ }^{16}$ or the presence of transversions in p53 in patients with viral hepatitis. ${ }^{17}$

By using this PCR technique we were able to detect N21I in three families with hereditary pancreatitis. In each case the screening data were confirmed by sequencing of the corresponding DNAs. Meanwhile more than 100 individuals with suspected hereditary pancreatitis have been analysed with this technique. Specificity seems to be very high: in all individuals which were negative on N21I screening, wild type DNA was found on sequencing. Furthermore, the mutations identified by our technique were all confirmed by sequencing.

Remarkably, the PCR technique developed for detection of the N21I mutation may also be used for identification of low frequencies of the mutation in the genome. This can be shown by analysis of the DNA bearing the N21I mutation diluted with wild type DNA. Whereas the control DNA did not show any specific amplification, in the presence of wild type DNA, up to a 500-fold dilution of mutated DNA showed a specific signal on the agarose gel. This implies that the technique can detect the N21I mutation at a frequency in the genome of less $0.2 \%$. Such mutations were not found in leucocyte DNA, pancreatic juice, or pancreatic tissue DNA obtained from patients with chronic alcoholic pancreatitis. These findings are strong evidence that somatic mutations of trypsinogen do not play a major role in the pathogenesis of alcoholic pancreatitis.

In the presence of wild type DNA the exon 3 $\mathrm{R} 117 \mathrm{H}$ mutation may not be detected at such a high sensitivity by restriction digestion. Use of an allele specific PCR, as was done here for the N21I mutation, is hampered by the presence of a GC rich region situated close to the $\mathrm{R} 117 \mathrm{H}$ mutation. However, at a frequency of about $10 \%$ in the cells present in pancreatic tissue or juice the mutation could still be detected by restriction digestion. Again we were unable to find this mutation in alcoholic pancreatitis.

It should be kept in mind that trypsinogen mutations other than the currently known ones may be risk factors for hereditary pancreatitis. In cystic fibrosis, for example, more than 600 CFTR mutations have been found. ${ }^{18}$ In hereditary pancreatitis a more stable trypsin was hypothesised to cause the disease. ${ }^{6}$ If this theory is correct, the trypsinogen mutation must stabilise the active enzyme, whereas in cystic fibrosis the mere destruction of the chloride transporter is sufficient. This makes it highly unlikely that the number of mutations is as high as in cystic fibrosis.

In conclusion, the $\mathrm{N} 21 \mathrm{I}$ and $\mathrm{R} 117 \mathrm{H}$ mutations of the cationic trypsinogen gene are not a major finding in chronic alcoholic pancreatitis and seem, therefore, not to play a pathogenic role in this disease. Increased trypsin activity, which is thought to be the decisive step in this type of pancreatitis, may arise via other mechanisms. ${ }^{19}$ The allele specific PCR we developed may be used as a reliable technique to screen for N21I, one of the high risk factors for hereditary pancreatitis.

The technical assistance of Susanne Kistner, Ute Kullrich, and Ines Sommerer is gratefully acknowledged. The study was supported in part by grant ufo 318 from Land Sachsen. There is a patent pending on the allele specific PCR described in this paper. The work was presented in part at the 1998 meeting of the American Gastroenterological Association, New Orleans, 1998;114:A473).

1 Steer ML, Waxman I, Freedman S. $N$ Engl $f \mathrm{Med}$ 1995;332:1482-90.

2 Mergener K, Baillie J. Chronic pancreatitis. Lancet 1997; 350:1379-85.

3 Werner J, Laposata M, Fernandez-del Castillo C, et al. Pancreatic injury in rats induced by fatty acids ethyl ester, a nonoxidative metabolite of alcohol. Gastroenterology 1997; 113:286-94.

4 Sibert JR. Hereditary pancreatitis in England and Wales. $\mathcal{F}$ Med Genet 1978;15:189-201.

5 Sossenheimer MJ, Aston CE, Preston RA, et al. Clinical characteristics of hereditary pancreatitis in a large family, based on high-risk haplotype. Am f Gastroenterol 1997;92: $1113-6$.

6 Whitcomb DC, Gorry MC, Preston RA, et al. Hereditary pancreatitis is caused by a mutation in the cationic trypsinogen gene. Nat Genet 1996;14:141-5.

7 Gorry MC, Gabbaizedeh D, Furey W, et al. Mutations in the cationic trypsinogen gene are associated with recurrent acute and chronic pancreatitis. Gastroenterology 1997;113: 1063-8.

8 Varallyay E, Pal G, Patthy A, et al. Two mutations in rat trypsin confer resistance against autolysis. Biochem Biophys Res Commun 1998;243:56-60.

9 Kattwinkel J, Lapey A, diSant'Agenese PA, et al. Hereditary pancreatitis: three new kindreds and a critical review of the pancreatitis: three new kindreds and
literature. Pediatrics 1973;51:55-69.

10 Sarner M, Cotton B. Classification of pancreatitis. Gut 1984;25:756-9.

11 Miller SA, Dykes DD, Polesky HF. A simple salting out procedure for extracting DNA from human nucleated cells. Nucleic Acids Res 1988;16:1215.

12 Lowenfels AB, Maisonneuve P, DiMagno EP, et al, and the International Hereditary Pancreatitis Study Group. Hereditary pancreatitis and the risk of pancreatic cancer. $\mathcal{F}$ Natl Cancer Inst 1997;89:442-6.

13 Rowen L, Koop BF, Hood L. The complete 685-kilobase DNA sequence of the human beta $\mathrm{T}$ cell receptor locus. Science 1996;272:1755-62.

14 Teich N, Mossner J, Keim V. Mutations of the cationic trypsinogen in hereditary pancreatitis. Hum Mutat 1998; 12:39-43.

15 Ge Z. Taylor DE. Rapid polymerase chain reaction screening of Helicobacter pylori chromosomal point mutations. Helicobacter 1997;2:127-31.

16 Norby S. Mutation-specific PCR: a rapid and inexpensive diagnostic method, as exemplified by mitochondrial DNA diagnostic method, as exemplified by mitochondrial DNA
analysis in Leber's hereditary optic neuropathy. DNA Cell Biol 1993;12:549-52.

17 Kirby GM, Batist G, Fotouhi-Ardakani N, et al. Allelespecific PCR analysis of p53 codon 249 AGT transversion in liver tissues from patients with viral hepatitis. Int $\mathcal{f}$ Cancer 1996;68:21-5.

18 Rosenstein BJ, Zeitlin PL. Cystic fibrosis. Lancet 1998;351: 277-82.

19 Steer ML, Meldolesi J. The cell biology of experimental pancreatitis. N Engl f Med 1987;316:144-50. 